\title{
Evaluasi Instalasi Pengolahan Air Limbah Industri Tepung Tapioka PT Sari Tani Sumatera, Serdang Bedagai
}

\author{
Amir Husin ${ }^{1}$, Muhammad Faisal ${ }^{2}$, Trisno Utomo Naibaho ${ }^{3 *}$ \\ 1,2,3Program Studi Teknik Lingkungan, Universitas Sumatera Utara (USU), Medan \\ Koresponden email: trisnoutomonaibaho@gmail.com
}

Diterima: 30 November 2021

Disetujui: 29 Desember 2021

\begin{abstract}
PT Sari Tani Sumatera uses the WWTP system in method stabilization pond with the aim that the level of wastewater produced can be reduced efficiently and naturally. But the biggest problem is, they have is in the environmental aspect of the generated wastewater because it contains cyanide compounds that have potential to pollute the Rambung River. In addition, physical factors and the dimensions of the pond also have a major influence on the industrial wastewater treatment of PT Sari Tani Sumatra. To prevent pollution, an evaluation was carried out in the form of an analysis of the discharge and wastewater content, as well as an analysis of the dimensions of the pond. From the evaluation results, there is a calculation of the discharge water discharge reaching $500 \mathrm{~m} 3 /$ day with the wastewater content dominated by BOD and Cyanide. Furthermore, in the analysis of the dimensions of the pond, there are 2 out of 9 ponds that have problems due to increasing the level of wastewater, even though the detention time and depth still meet the design criteria for the dimensions of the pond. In order to obtain optimal WWTP processing, it is necessary to recommend recommendations from the evaluation results.
\end{abstract}

Keywords: evaluation, tapioca flour industry, pond, waste water, cassava

\begin{abstract}
Abstrak
PT Sari Tani Sumatera menggunakan sistem IPAL metode Kolam Stabilisasi dengan tujuan supaya kadar air limbah yang dihasilkan bisa berkurang secara efisien dan alamiah. Tetapi permasalahan terbesar yang dimiliki adalah dalam aspek lingkungan dari limbah cair yang dihasilkan karena terkandung senyawa sianida yang berpotensi mencemari Sungai Rambung. Selain itu, faktor fisik dan dimensi kolam juga berpengaruh besar dalam pengolahan air limbah industri PT Sari Tani Sumatera. Untuk mencegah pencemaran terjadi, maka dilakukan evaluasi berupa analisis debit dan kadar air limbah, serta analisis dimensi kolam. Dari hasil evalusi, terdapat perhitungan debit air buangan mencapai $500 \mathrm{~m}^{3} / \mathrm{hari}$ dengan kadar air limbah didominasi oleh BOD dan Sianida. Selanjutnya dalam analisis dimensi kolam, terdapat 2 dari 9 kolam yang bermasalah karena menaikkan kadar air limbah, walau waktu detensi dan kedalaman masih memenuhi kriteria desain dimensi kolam. Agar dapat mendapatkan pengolahan IPAL yang optimal, maka perlu rekomendasi dari hasil evaluasi.
\end{abstract}

Kata Kunci: evaluasi, industri tepung tapioka, kolam, limbah cair. singkong

\section{Pendahuluan}

Jika semakin maju tingkat perkembangan perindustrian di suatu negara atau daerah, maka makin banyak jumlah dan macam industri. Akibatnya akan memunculkan sifat kegiatan dan usaha tersebut serta besarnya dan banyaknya kebutuhan yang harus dipenuhi secara kompleks [1]. Hal tersebut selaras dengan kemajuan ilmu pengetahuan dan teknologi, juga akan menambahkan jumlah penduduk dengan mobilitas yang sangat cepat sebagai pengaruh terhadap upaya pemenuhan keutuhan manusia (baik kebutuhan dasar seperti pangan dan sandang, serta kebutuhan materil sebagai hasil proses industri). Akibatnya, akan memunculkan kecenderungan peningkatan aktivitas yang menghasilkan buangan seperti limbah. Berdasarkan perkembangan pesat industri yang semakin meningkat, maka akan menghasilkan buangan (limbah) yang diperoleh dari hasil industri [2].

Jika semakin besarnya laju perkembangan penduduk dan industrialisasi di Indonesia, maka telah mengakibatkan terjadinya penurunan kualitas lingkungan juga. Padatnya pemukiman dan kondisi sanitasi lingkungan yang buruk serta buangan industri yang langsung dibuang tanpa proses pengolahan terlebih dahulu telah menyebabkan pencemaran di sebagian besar daerah di Indonesia [3]. Keberadaan suatu industri ialah menciptakan lapangan pekerjaan, menyejahterakan karyawan dan berperan dalam peningkatan perekonomian daerah. Untuk itu, tugas industri harus tetap menghasilkan profit (keuntungan) agar tetap mampu melaksanakan peran itu. Pengelolaan industri harus memenuhi ketentuan dan aturan yang 
berlaku serta jangan sampai ada industri yang mencemari lingkungan. Industri sejatinya harus dapat mengelola lingkungan tersebut sesuai dengan tata kelola industri yang baik pula [4].

Maka dari itu, industri dituntut memberikan dan menjamin keamanan kepada masyarakat atau komunitas, melalui pengendalian pencemaran lingkungan hidup dengan benar. Pihak pengelola di industri yang dimulai dari tingkatan manajemen (lapisan pengelola) sampai dengan semua karyawan di industri penting untuk menjalankan pengendalian lingkungan hidup yang benar dan efektif secara mandiri dan aktif, diatas kesadaran tentang pentingnya pengendalian terkait antisipasi pencemaran lingkungan hidup. Hal tersebut akan mampu mencegah pencemaran lingkungan hidup secara dini, atau mampu menemukan dengan cepat permasalahan pencemaran lingkungan hidup itu juga [5].

Umumnya, lingkungan hidup memiliki daya tamping buangan (seperti limbah) yang terbatas. Ketika limbah yang dibuang tidak melebihi ambang batas, lingkungan masih dapat menguraikannya sehingga tidak menimbulkan pencemaran. Tetapi jika ambang batas tersebut terlampaui, maka lingkungan tidak dapat menetralisir limbah yang ada sehingga timbul masalah pencemaran dan degradasi kondisi lingkungan. Maka dari itu, lingkungan hidup harus dijaga kelestariannya dari pencemaran dengan pengolahan limbah yang baik [6]. Pada abad terakhir, pertumbuhan populasi dan industrialisasi telah mengakibatkan degradasi lingkungan yang signifikan. Pembuangan air limbah yang tidak diolah di darat atau di arus (stream) dan sungai tidak lagi menjadi pilihan. Itulah sebabnya peraturan yang lebih baru ditujukan untuk melindungi lingkungan serta kesehatan masyarakat [7].

Secara harfiah ada berbagai jenis limbah cair untuk kawasan industri. Antara lain: [8]

* Air limbah dari karyawan. Kuantitasnya diberikan oleh konsumsi; kualitasnya sesuai dengan air limbah dari pemukiman kecil dan kota - diolah secara terpisah.

* Air hujan - Ini dapat ditandai dengan curah hujan, di daerah tangkapan air, yang harusnya dikeringkan; kontaminasi tergantung pada kemurnian daerah tangkapan.

* Air teknologi, dikeluarkan dari proses pembuatan, kuantitas dan komposisinya diberikan oleh keanekaragaman produksi (konsumsi air per unit produksi)

* Air pendingin relatif bersih dan selalu diresirkulasi, bagian air secara bertahap dikuras dari sirkuit pendingin di beberapa perangkat penting.

* Air dalam sistem energik selalu diresirkulasi, tetapi sistem menghasilkan limbah dari pengolahan air tambahan, yang terkandung mineral berkonsentrasi tinggi.

Limbah industri berasal dari sumber dari kegiatan industri yang mana disebabkan oleh proses, baik secara langsung maupun tidak langsung juga. Limbah yang bersumber secara langsung dari kegiatan industri adalah limbah yang terproduksi bersamaan dengan proses produksi sedang berlangsung (saat produk dan limbah hadir pada waktu bersamaan). Limbah tidak langsung terproduksi sebelum proses maupun sesudah proses produksi [9].

Berdasarkan karakteristiknya, air limbah industri secara garis besarnya dapat dibagi menjadi beberapa kelompok, yaitu: [10]

* Air limbah industri yang terkandung konsentrasi zat organik yang relatif tinggi. Contohnya seperti industri makanan, industri kimia, industri minyak nabati atau hewani, industri obat-obatan, industri tekstil, dan lain-lain.

* Air limbah industri yang terkandung konsentrasi zat organik yang relatif rendah. Contohnya: industri pengemasan makanan, industri serat, industri kimia, industri minyak, industri batubara, industri laundry, dan lain-lain.

* Air limbah industri yang terkandung zat organik berbahaya dan beracun. Contohnya industri besi baja, industri kimia insektisida, herbisida, industri penyamakan kulit, dan lain-lain.

* Air limbah industri yang terkandung zat anorganik umum. Contohnya industri kimia seperti industri pupuk anorganik, industri kimia anorganik, industri keramik, dan lain-lain.

* Air limbah industri yang terkandung zat anorganik berbahaya dan beracun. Contohnya industri baterai, industri pelapisan logam (electroplatting), dan lain-lain.

Menurut data FAOSTAT di bulan Oktober 2011, Indonesia adalah negara di Asia (setelah Thailand) yang memproduksi singkong erbesar untuk membuat tepung tapioka sebanyak 22.039 .000 ton ubi dengan lahan seluas 1.176 .000 ha. Ragi singkong yang dihasilkan mencapai 18,5 ton per hektarnya. Lalu industri tepung tapioka di Indonesia jika mengingat sistem pertaniannya, tidak membutuhkan irigasi dan memetik singkong tersebut dengan menggunakan tangan. Ongkos produksi dalam menanam dan panen ubi saja per hektar dihargai 1.455 US\$ dan ongkos produksi untuk per ton singkongnya dihargai sebesar 78 US\$ [11].

Dalam kasus limbah cair industri tepung tapioka, limbah yang dihasilkan oleh pengolahan singkong 
bisa padat dan cair. Limbah cair tidak hanya tercipta dari proses pencucian atau pengupasan juga. Sebagian besar, kasus dari limbah cair dari pabrik pengolahan menjadi perhatian utama bagi masyarakat. Limbah cair yang dihasilkan dari pengolahan singkong dari industri tepung tapioka sangat berbau tidak sedap. Hal ini disebabkan oleh adanya kandungan mikroba yang tinggi pada limbah cair tersebut. Tetapi dengan efek berbahaya yang mungkin terjadi, air ini entah kenapa dibuang langsung oleh pabrik begitu saja ke tanah dan sungai atau aliran terdekat. Akibatnya bisa berisiko tinggi bagi lingkungan melalui pengurangan kualitas aliran. Dari kasus ini, menjadikan lebih banyak kendala bisnis jika manajemen yang tepat tidak diperhitungkan. Semuanya harus bergantung pada metode pengolahan dan teknologi yang diterapkan di pabrik pengolahan singkong [12]. Dalam limbah cair industri tepung tapioka, terdapat lima parameter umum yang harus diperhatikan. Lima parameter tersebut antara lain:

1. Padatan (Solids)

Padatan (Solids) diklasifikasikan menjadi dua golongan umum yakni padatan terlarut (Dissolved Solid) dan padatan tersuspensi (Suspended Solid). Jenis padatan terlarut maupun padatan tersuspnsi dapat bersifat organik ataupun anorganik tergantung dari sumber asal limbahnya (termasuk limbah cair). Padatan tersuspensi memiliki diameter yang lebih besar daripada padatan terlarut, yakni antara $0,01 \mathrm{~mm}$ sampai dengan $0.001 \mathrm{~mm}$. [9]

\section{BOD (Biological Oxygen Demand)}

BOD adalah jumlah oksigen yang dibutuhkan mengoksidasi senyawa organik dalam limbah cair oleh mikroba pada suhu $20{ }^{\circ} \mathrm{C}$ selama waktu inkubasi 5 hari. Biasanya BOD digunakan sebagai parameter dengan bertujuan untuk mengetahui senyawa kimia organik dalam limbah cair [13].

\section{COD (Chemical Oxygen Demand)}

Nilai kadar COD di dalam air buangan/air limbah selalu lebih tinggi daripada nilai kadar BOD. Hal ini disebabkan oleh senyawa kimia dalam komposisi lebih banyak dapat dioksidasi secara kimia jika dibandingkan dengan oksidasi biologis. Jika tinggi nilai kadar COD dalam air limbah tersebut dapat menandakan bahwa derajat pencemaran pada suatu perairan juga tinggi [3].

4. $\mathrm{pH}$

Dalam keadaan normal, air memiliki tingkat keasaman sekitar 6.0-7.5. Tetapi tingkat keasaman pada air dapat berubah diakibatkan oleh adanya senyawa kimia buangan pada air. Sumber utama asam di dalam air berasal dari air limbah pertambangan dan bahan buangan industri. Sumber utama penyebab basa pada air disebabkan oleh peningkatan aktivitas manusia seperti penambahan jenis pupuk tertentu untuk meningkatkan $\mathrm{pH}$ air atau penambahan senyawa basa ke dalam air di dalam proses pengolahan produk tambang. Tentu saja berbeda dengan $\mathrm{pH}$ garam dimana sumber penyebabnya yakni dari aktivitas manusia seperti penambahan pupuk ke dalam pengairan sawah. Hal tersebut menyebabkan peningkatan salinitas air atau peningkatan konsentrasi senyawa kimia di dalam air yang bisa membuat air menjadi menguap secara alamiah ketika musim kemarau terjadi [14].

5. Sianida

Senyawa beracun sianida juga menjadi senyawa kimia pencemar air, terkhusus untuk daerah tambang emas dan perak. Senyawa sianida seperti natrium sianida $(\mathrm{NaCN})$ dan Kalium Sianida $(\mathrm{KCN})$ digunakan untuk mengekstraksi emas dan perak dari mineral. Limbah dari senyawa sianida akan menyebabkan pencemaran air yang berasal dari hasil pencucian dan dibuang ke dalam saluran air dan tanah [14]. Untuk nilai baku mutu air limbah dari industri tepung tapioka, bisa diketahui kadar dan beban pencemaran paling tinggi juga. Hal ini bertujuan agar mengetahui dan menerapkan proses pembuangan akhir air limbah industri tepung tapioka tersebut dapat diterima ke badan air dalam angka kadarnya lebih kecil dari nilai baku mutu yang ditentukan. Nilai baku mutu dapat diperlihatkan dalam Tabel 1.

Tabel 1. Baku mutu air limbah industri tepung tapioka

\begin{tabular}{lcc}
\hline Parameter & $\begin{array}{c}\text { Kadar Paling Tinggi } \\
(\mathrm{mg} / \mathrm{L})\end{array}$ & $\begin{array}{c}\text { Beban Pencemaran } \\
\text { Paling Tinggi }(\mathrm{kg} / \mathrm{ton})\end{array}$ \\
\hline BOD $_{5}$ & 150 & 4,5 \\
COD & 300 & 9 \\
TSS & 100 & 3 \\
Sianida $(\mathrm{CN})$ & 0,3 & 0,009 \\
pH & \multicolumn{2}{c}{$6,0-9,0$} \\
\hline Debit Limbah Paling Tinggi & \multicolumn{2}{c}{$30 \mathrm{~m}^{3}$ per-ton produk tapioka } \\
\hline \multicolumn{2}{c}{ Sumber: Lampiran V Peraturan Menteri Lingkungan Hidup Nomor 5 Tahun 2014. }
\end{tabular}


Untuk mengatasi masalah pada bentuk maupun kadar limbah cair industri tepung tapioka tersebut, maka harus dibangun Instalasi Pengolahan Air Limbah (IPAL). Tujuan utama adanya Instalasi Pengolahan Air Limbah (IPAL) adalah untuk memenuhi standar kualitas efluen yang ditetapkan oleh otoritas pengaturan atau peraturan federal, negara bagian, nasional, regional, dan lokal; dan untuk mencegah banyak kondisi lingkungan yang merugikan yang mungkin berkembang karena pengolahan air limbah yang tidak memadai [15].

Untuk permasalahan limbah cair PT Sari Tani Sumatera, dibalik proses pengolahan singkong menjadi tepung tapioka tentu saja akan menghasilkan limbah cair dari sisa proses pengolahan tersebut. Walaupun begitu, limbah cair tepung tapioka yang dihasilkan oleh PT Sari Tani Sumatera dapat dikelola dan diolah dengan baik dengan menggunakan sistem Instalasi Pengolahan Air Limbah (IPAL) dengan metode pengolahan sistem kolam stabilisasi. Akan tetapi, IPAL PT. Sari Tani Sumatera memiliki kelemahan yang signifikan. Seperti cara pengolahannya, dimensi bangunan, hingga dampak dari air outlet/ effluent yang dikeluarkan ke sungai terdekatnya (yakni sungai Rambung). Di sisi lain, limbah cair (air buangan) PT Sari Tani Sumatera secara harfiah memiliki masalah seperti bentuk warna dan kualitas kadar air outlet/ effluent yang dihasilkan. Hal itu akan berpotensi mengganggu keanekaragaman hayati di sungai dan dianggap turut menyumbang proses degradasi penjernihan air sungai di dekat pabrik tersebut.

Adapun tujuan dalam melakukan evaluasi Instalasi Pengolahan Air Limbah (IPAL) industri tepung tapioka di PT Sari Tani Sumatera, Serdang Bedagai antara lain:

1. Mengevaluasi sistem pengolahan air limbah dalam kondisi aman bagi lingkungan secara optimal dengan metode pengolahan sistem kolam stabilisasi.

2. Mendapatkan kesimpulan lainnya dan memberikan masukan/rekomendasi kepada PT Sari Tani Sumatera berdasarkan hasil perhitungan dan hasil evaluasi yang diperoleh terhadap unit IPAL PT Sari Tani Sumatera.

\section{Metode Penelitian}

Tahapan evaluasi IPAL meliputi langkah-langkah pelaksanaan evaluasi dari awal sampai akhir evaluasi tersebut. Tahapan evaluasi ini dimulai dengan mengidentifikasi lahan dan jenis Instalasi Pengolahan Air Limbah (IPAL) PT Sari Tani Sumatera, Serdang Bedagai terlebih dahulu. Setelah itu melakukan studi dan perhitungan untuk penentuan perencanaan dan perancangan dengan memberikan rekomendasi. Layout IPAL PT Sari Tani Sumatera yang akan dievaluasi dapat dilihat pada Gambar 1 dan untuk melaksanakan evaluasi ini, dilakukan dengan alur metode evaluasi seperti Gambar 2.

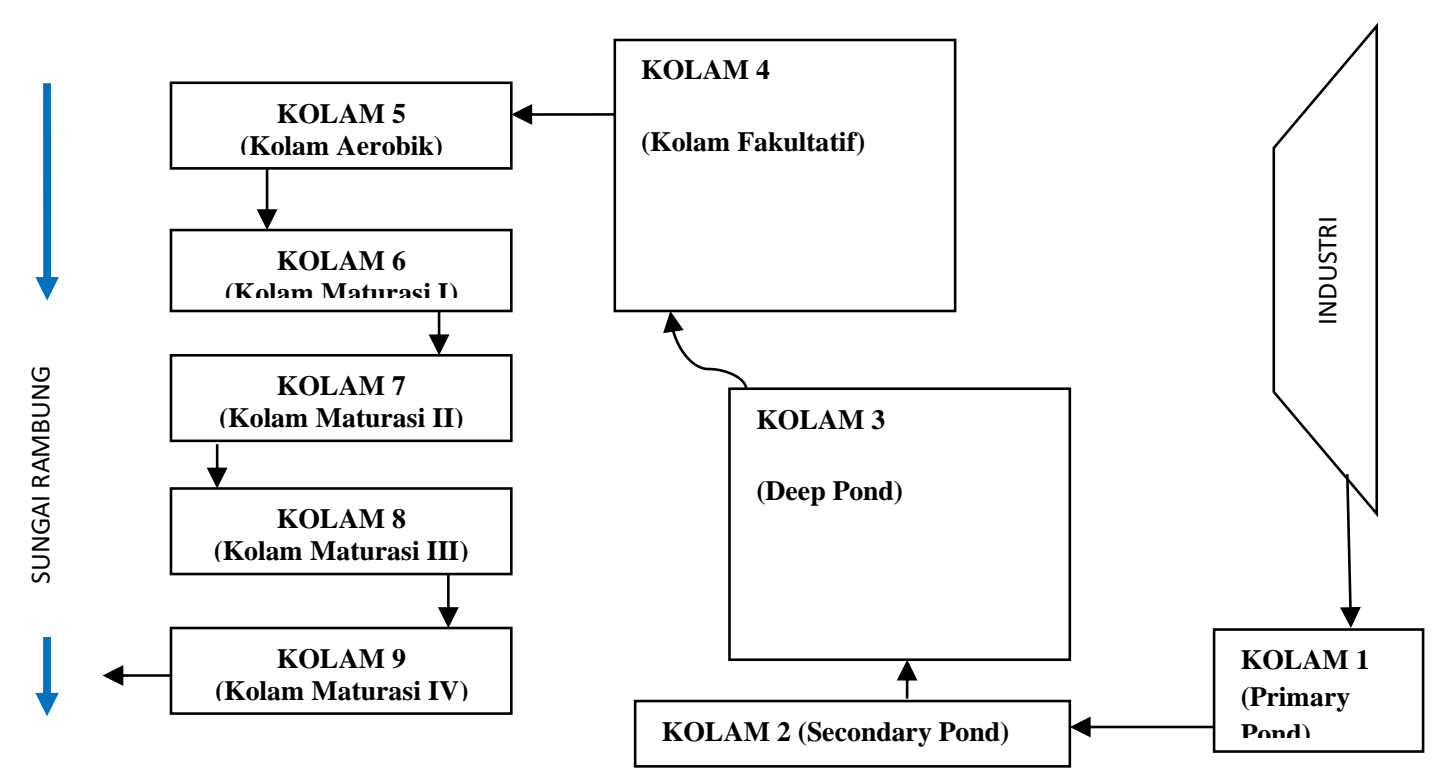

Gambar 1. Diagram layout jalur skematik IPAL PT Sari Tani Sumatera Sumber: Data penelitian, 2021 


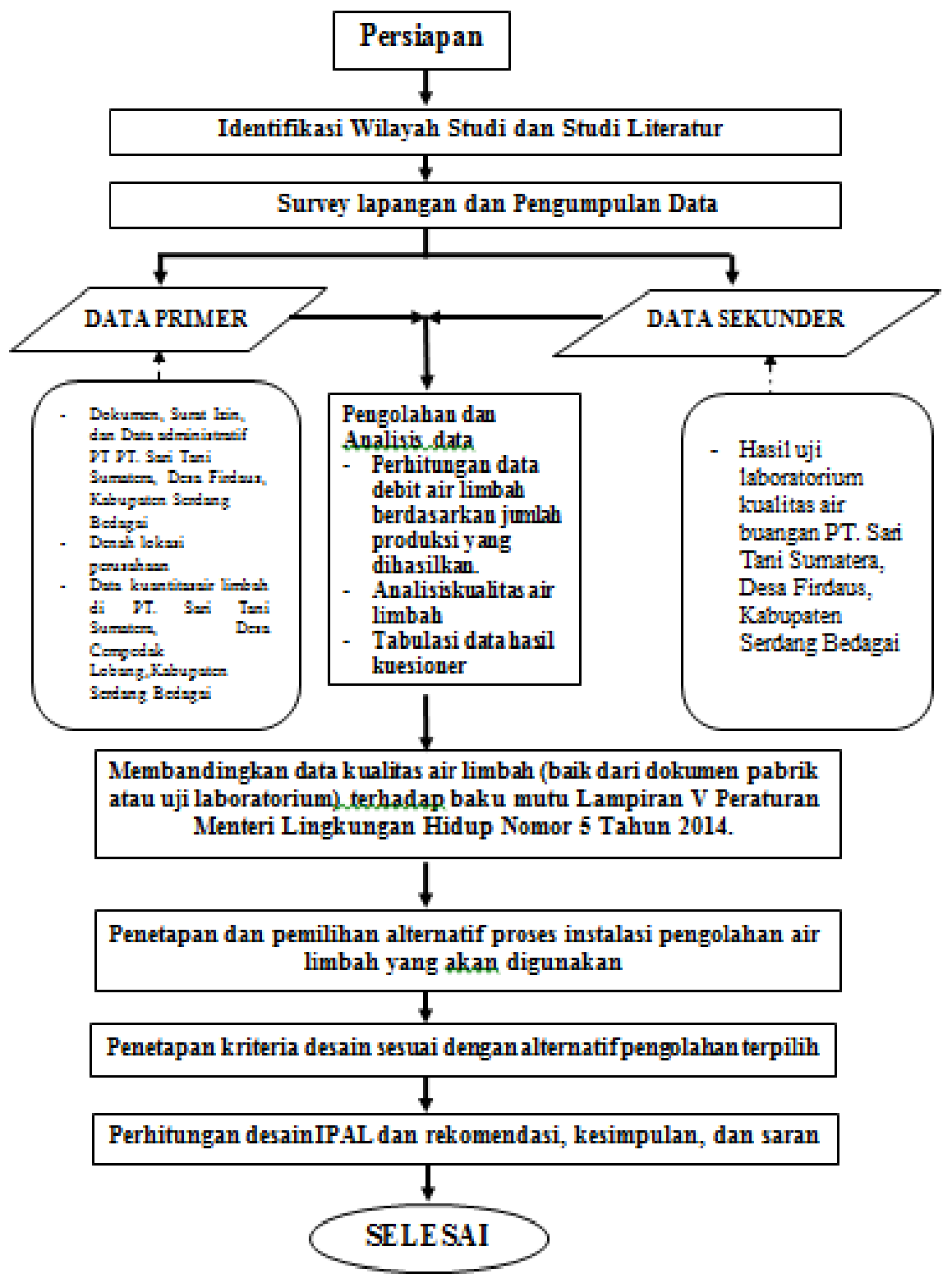

Gambar 2. Diagram alir perencanaan evaluasi Sumber: Data penelitian, 2021

\section{Hasil dan Pembahasan}

\subsection{Metode pengukuran efisiensi kolam dan baku mutu alternatif}

Untuk mendapatkan pengukuran efisiensi kolam pada tahap awal dilakukan dengan mengukur hasil uji parameter limbah cair di laboratorium. Dari hasil yang diperoleh ternyata nilai efisiensi kolam untuk pengolahan limbah cair sebesar $62 \%$ pada kolam 9. Meskipun demikian, efisiensi kolam terendah ada di kolam 2 (secondary pond) dengan nilai 10,72 persen. Untuk rinciannya dapat dilihat pada Tabel 2. 
Tabel 2. Efisiensi setiap kolam

\begin{tabular}{|c|c|c|c|c|c|c|c|c|c|c|c|c|c|}
\hline \multirow[t]{2}{*}{ KOLAM } & \multicolumn{3}{|c|}{ BOD } & \multicolumn{3}{|c|}{ COD } & \multicolumn{3}{|c|}{ TSS } & \multicolumn{3}{|c|}{ SIANIDA } & \multirow[t]{2}{*}{$E K$} \\
\hline & $I$ & $O$ & $R E$ & $I$ & $O$ & $R E$ & $I$ & $O$ & $R E$ & $I$ & $O$ & $R E$ & \\
\hline $\begin{array}{l}\text { KOLAM } 1 \\
\text { (Primary Pond) }\end{array}$ & 2510 & 1204 & 52,03 & 5240 & 2485 & 52,57 & 830 & 394 & 52,53 & 5,25 & 2,51 & 52,19 & 52,33 \\
\hline $\begin{array}{l}\text { KOLAM } 2 \\
\text { (Secondary } \\
\text { Pond) }\end{array}$ & 1204 & 1021 & 15,19 & 2485 & 2272 & 8,57 & 394 & 361 & 8,37 & 2,51 & 2,24 & 10,75 & 10,72 \\
\hline $\begin{array}{l}\text { KOLAM } 3 \\
\text { (Deep Pond) }\end{array}$ & 1021 & 802 & 21,44 & 2272 & 1781 & 21,61 & 361 & 283 & 21,6 & 2,24 & 1,72 & 23,21 & 21,97 \\
\hline $\begin{array}{l}\text { KOLAM } 4 \\
\text { (Kolam } \\
\text { Fakultatif) }\end{array}$ & 802 & 451 & 43,76 & 1781 & 963 & 45,92 & 283 & 109 & 61,48 & 1,72 & 0,95 & 44,76 & 48,98 \\
\hline $\begin{array}{l}\text { KOLAM } 5 \\
\text { (Kolam } \\
\text { Aerobik) }\end{array}$ & 451 & 55,19 & 87,76 & 963 & 620,24 & 35,59 & 109 & 356,2 & $\begin{array}{c}-226,78 \\
*)\end{array}$ & 0,95 & 0,79 & 16,84 & $\begin{array}{c}-21,64 \\
*)\end{array}$ \\
\hline $\begin{array}{l}\text { KOLAM } 6 \\
\text { (Kolam } \\
\text { Maturasi I) }\end{array}$ & 55,19 & 42,20 & 23,53 & 620,24 & 439,70 & 29,1 & 356,2 & 246,4 & 30,82 & 0,79 & 0,56 & 29,11 & 28,14 \\
\hline $\begin{array}{l}\text { KOLAM } 7 \\
\text { (Kolam } \\
\text { Maturasi II) }\end{array}$ & 1421 & 906 & 36,24 & 3289 & 1835 & 44,2 & 522 & 291 & 44,25 & 3,26 & 1,81 & 44,47 & 42,29 \\
\hline $\begin{array}{l}\text { KOLAM } 8 \\
\text { (Kolam } \\
\text { Maturasi III) }\end{array}$ & 906 & 601 & 33,66 & 1835 & 1221 & 33,46 & 291 & 194 & 33,33 & 1,81 & 1,21 & 33,14 & 33,29 \\
\hline $\begin{array}{l}\text { KOLAM } 9 \\
\text { (Kolam } \\
\text { Maturasi IV) }\end{array}$ & 601 & 210 & 65,05 & 1221 & 459 & 62,4 & 194 & 73 & 62,37 & 1,21 & 0,50 & 58,67 & 62,12 \\
\hline
\end{tabular}

Sumber: Data penelitian, 2021

Keterangan:

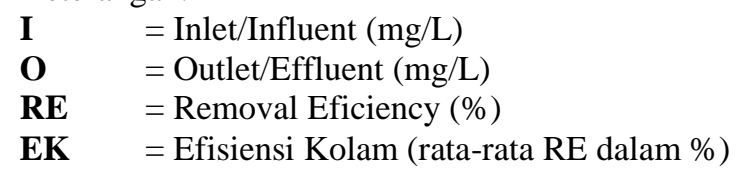

*) Nilai data didapat berdasarkan nilai baku mutu kolam 4 (kolam fakultatif) tahun 2019, dan terjadi perbedaan signifikan di dalamnya karena dibandingkan dengan data baru (2020). TSS tidak dilibatkan, dan nilai efisiensi kolam 5 sebenarnya adalah $21,64 \%$

Selanjutnya dari penggabungan dan penyederhanaan data awal dan data uji ulang, diperoleh data perbandingan alternatif untuk mendapatkan nilai parameter yang diperoleh. Hasilnya nilai parameter pada setiap kolam semakin hari semakin menurun. Untuk lebih detilnya dapat dilihat pada Tabel 3.

Tabel 3. Data perbandingan alternatif

\begin{tabular}{lcccccc}
\hline \multicolumn{1}{c}{ Hasil Uji } & $\begin{array}{c}\text { Efisiensi } \\
\text { Kolam }(\%)\end{array}$ & $\begin{array}{c}\text { BOD } \\
(\mathrm{mg} / \mathrm{L})\end{array}$ & $\begin{array}{c}\text { COD } \\
(\mathrm{mg} / \mathrm{L})\end{array}$ & $\begin{array}{c}\text { TSS } \\
(\mathrm{mg} / \mathrm{L})\end{array}$ & $\begin{array}{c}\mathrm{pH} \\
(\mathrm{mg} / \mathrm{L})\end{array}$ \\
\hline Baku Mutu $*$ ) & - & 150 & 300 & 100 & $6,0-9,0$ & 0,3 \\
KOLAM 1 (Primary Pond) & 52,33 & $1.313,48$ & 2.742 & 434,3 & 4,99 & 2,74 \\
KOLAM 2 (Secondary Pond) & 10,72 & 109,77 & 266,39 & 42,23 & 6,58 & 0,26 \\
KOLAM 3 (Deep Pond) & 21,97 & 224,31 & 499,15 & 79,31 & 6,47 & 0,49 \\
KOLAM 4 (Kolam Fakultatif) & 48,98 & 392,81 & 872,33 & 138,6 & 6,80 & 0,85 \\
KOLAM 5 (Kolam Aerobik) & 21,64 & 97,6 & 208,3 & 23,58 & 7,01 & 0,20 \\
KOLAM 6 (Kolam Maturasi I) & 28,14 & 15,53 & 174,53 & 100,23 & 7,16 & 0,22 \\
KOLAM 7 (Kolam Maturasi II) & 42,29 & 17,84 & 185,94 & 104,2 & 6,88 & 0,23 \\
KOLAM 8 (Kolam Maturasi III) & 33,29 & 5,93 & 61,9 & 34,68 & 7,24 & 0,076 \\
KOLAM 9 (Kolam Maturasi IV) & 62,12 & 3,68 & 38,45 & 21,54 & 7,35 & 0,047 \\
\hline
\end{tabular}

Sumber: Data penelitian, 2021

Berdasarkan data Tabel 3, bisa digambarkan melalui grafik ini pada Gambar 3. Pada grafik ini, terlihat bahwa nilai parameter BOD, COD, dan TSS pada Kolam 3 (Deep Pond) pada mulanya naik. Lalu berlanjut hingga ke kolam 4 (Kolam Fakultatif) hingga akhirnya turun lagi di kolam 5 (Kolam Aerobik). Untuk lebih jelasnya dapat dilihat pada Gambar 3. 


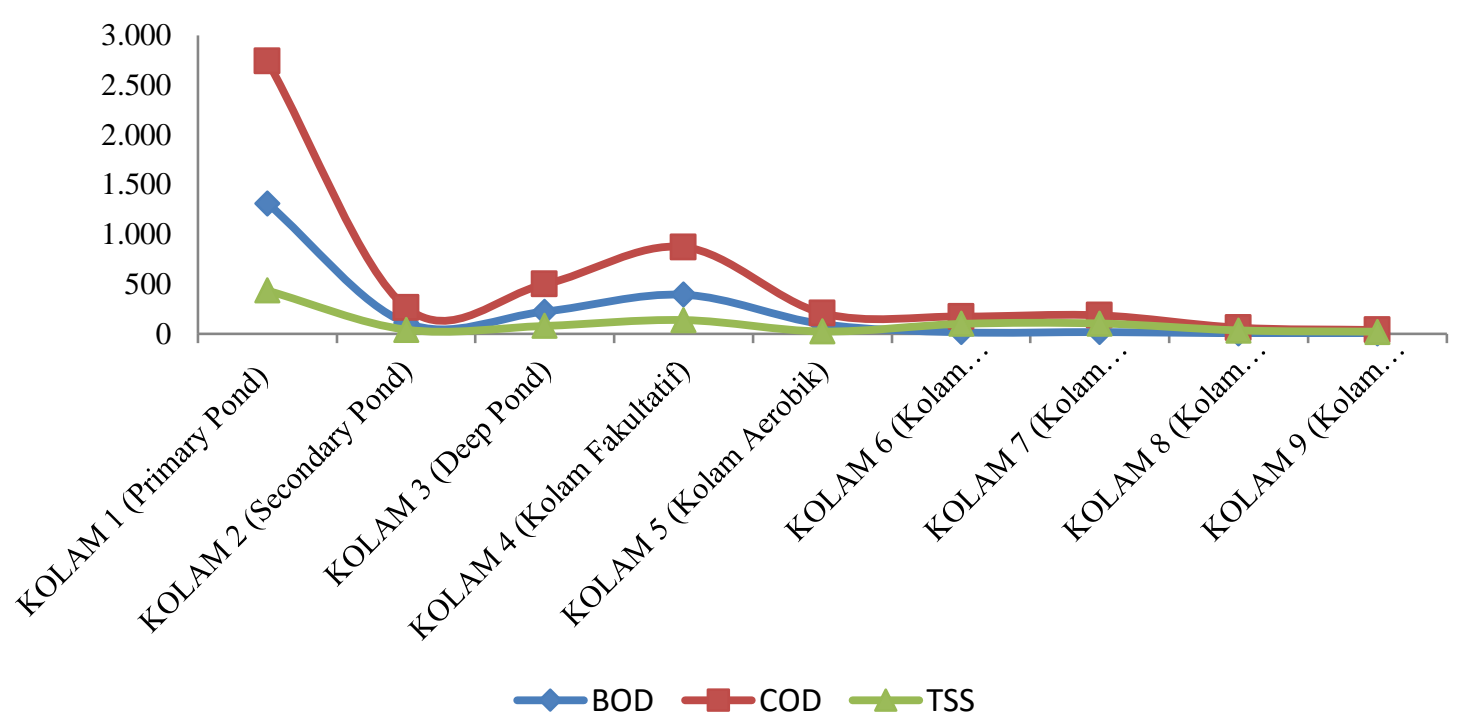

Gambar 3. Diagram parameter BOD, COD, dan TSS (dalam mg/L) berdasarkan data perbandingan alternatif Sumber: Data penelitian, 2021

Lalu untuk perhitungan $\mathrm{pH}$ dan Sianida, pada Gambar 4 terlihat bahwa nilai parameter $\mathrm{pH}$ dan Sianida pada Kolam 3 (Deep Pond) pada mulanya juga naik. Lalu berlanjut hingga ke kolam 4 (Kolam Fakultatif) hingga akhirnya turun lagi di kolam 5 (Kolam Aerobik). Hal ini dapat dilihat pada Gambar 4.

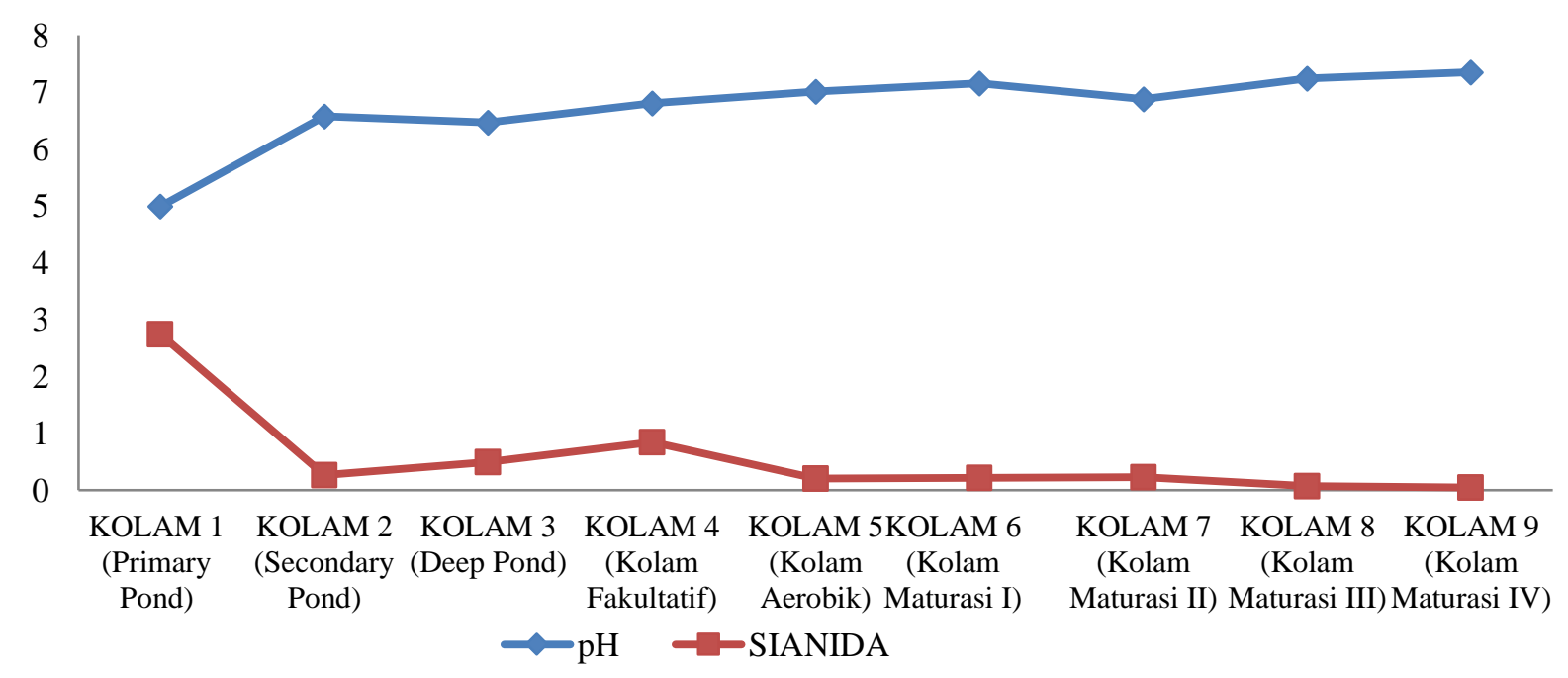

Gambar 4. Diagram parameter $\mathrm{pH}$ dan Sianida (dalam $\mathrm{mg} / \mathrm{L}$ ) berdasarkan data perbandingan alternatif Sumber: Data penelitian, 2021

\subsection{Metode pengukuran data debit limbah cair minimum dan waktu detensi}

Pertama-tama, dilakukan pengukuran luas lahan luas lahan kolam dari hasil perkalian panjang dan lebar dari masing-masing kolam. Lalu juga diukur kedalaman awal dan kedalaman eksisting. Hasilnya dapat dilihat pada Tabel 4. 


\begin{tabular}{lccccccc}
\hline \multicolumn{1}{c}{ Tabel 4. Waktu detensi berdasarkan debit limbah cair minimum pada kedalaman awal dan kedalaman eksisting } \\
\hline & $\begin{array}{c}\text { Panjang } \\
(\mathrm{m})\end{array}$ & $\begin{array}{c}\text { Lebar } \\
(\mathrm{m})\end{array}$ & $\begin{array}{c}\text { Ke- } \\
\text { dalaman } \\
\text { awal }(\mathrm{m})\end{array}$ & $\begin{array}{c}\text { Ke- } \\
\text { dalaman } \\
\text { eksisting } \\
(\mathrm{m})\end{array}$ & $\begin{array}{c}\text { Selisih } \\
\text { Ke- } \\
\text { dalaman } \\
(\mathrm{m})\end{array}$ & $\begin{array}{c}\text { Luas } \\
\text { Lahan } \\
\text { Kolam } \\
\left(\mathrm{m}^{2}\right)\end{array}$ & $\begin{array}{c}\text { Ke-dalaman } \\
\text { awal } \\
(\mathrm{m} / \text { detik })\end{array}$ \\
\hline KOLAM 1 (Primary Pond) & 48 & 22 & 4 & 1,6 & $-2,4$ & 1.056 & 0,5 \\
KOLAM 2 (Secondary Pond) & 32 & 22 & 4 & 3,4 & $-0,6$ & 704 & 0,57 \\
KOLAM 3 (Deep Pond) & 50 & 18 & 5 & 3,5 & $-1,5$ & 900 & 0,37 \\
KOLAM 4 (Kolam Fakultatif) & 72 & 20 & 5 & 1,3 & $-3,7$ & 1.440 & 0,57 \\
KOLAM 5 (Kolam Aerobik) & 58 & 18 & 5 & 3,5 & $-1,5$ & 1.044 & 0,65 \\
KOLAM 6 (Kolam Maturasi I) & 58 & 18 & 5 & 3,5 & $-1,5$ & 1.044 & 0,47 \\
KOLAM 7 (Kolam Maturasi II) & 58 & 18 & 5 & 3,5 & $-1,5$ & 1.044 & 0,47 \\
KOLAM 8 (Kolam Maturasi III) & 58 & 18 & 5 & 3,2 & $-1,8$ & 1.044 & 0,47 \\
KOLAM 9 (Kolam Maturasi IV) & 58 & 18 & 5 & 3 & -2 & 1.044 & 0,47 \\
& 492 & 172 & 43 & 26,5 & $-16,5$ & 9.320 & 4,54 \\
\hline
\end{tabular}

\subsection{Metode analisis rekomendasi}

Hasil daripada metode analisis rekomendasi dapat dilihat pada tabel berikut. Disini yang perlu ditinjau kembali hanya waktu tinggal dan kedalamannya, serta efisiensi yang kecil pada Kolam 3 (Deep Pond). Karena pengolahan aerobik tidak efektif, maka dilakukan pengolahan secara anaerobik agar bisa menurunkan kadar BOD yang diperoleh dari kolam 2 (Secondary Pond). Untuk melihat hasil analisis rekomendasi lebih lanjut dapat dilihat pada Tabel 5.

Tabel 5. Analisis rekomendasi berupa kesimpulan akhir setiap unit IPAL PT Sari Tani Sumatera

\begin{tabular}{|c|c|c|c|c|c|c|c|c|c|}
\hline \multirow[t]{2}{*}{$\begin{array}{l}\text { Unit } \\
\text { IPAL }\end{array}$} & \multirow[t]{2}{*}{$\mathrm{pH}$} & \multirow{2}{*}{$\begin{array}{l}\text { Luas } \\
\text { Lahan } \\
\text { Kolam } \\
\left(\mathrm{m}^{2}\right)\end{array}$} & \multicolumn{2}{|c|}{ Efisiensi } & \multicolumn{2}{|c|}{ Desain Awal } & \multicolumn{2}{|c|}{$\begin{array}{c}\text { Berdasarkan Desain } \\
\text { Eksisting }\end{array}$} & \multirow[t]{2}{*}{ Keterangan } \\
\hline & & & $\begin{array}{c}\text { BOD REMOVAL } \\
(\%)\end{array}$ & KOLAM (\%) & $\begin{array}{c}\text { Waktu } \\
\text { Tinggal } \\
\text { (Hari) }\end{array}$ & $\begin{array}{c}\mathrm{Ke}- \\
\text { dalaman } \\
(\mathrm{m})\end{array}$ & $\begin{array}{c}\text { Waktu } \\
\text { Tinggal } \\
\text { (Hari) }\end{array}$ & $\begin{array}{c}\text { Ke- } \\
\text { dalaman } \\
(\mathrm{m})\end{array}$ & \\
\hline $\begin{array}{l}\text { KOLAM } 1 \\
\text { (Primary } \\
\text { Pond) }\end{array}$ & 4,99 & 1.056 & 52,03 & 52,33 & 8,7 & 4 & 3,49 & 1,6 & $\begin{array}{c}\text { Sesuai kriteria } \\
\text { desain }\end{array}$ \\
\hline $\begin{array}{l}\text { KOLAM } 2 \\
\text { (Secondary } \\
\text { Pond) }\end{array}$ & 6,58 & 704 & 15,19 & 10,72 & 5,95 & 4 & 5 & 3,4 & $\begin{array}{c}\text { Sesuai kriteria } \\
\text { desain }\end{array}$ \\
\hline $\begin{array}{l}\text { KOLAM } 3 \\
\text { (Deep Pond) }\end{array}$ & 6,47 & 900 & 21,44 & 21,97 & 9,8 & 5 & 6,8 & 3,5 & $\begin{array}{c}\text { Perlu } \\
\text { peninjauan } \\
\text { kembali }\end{array}$ \\
\hline $\begin{array}{l}\text { KOLAM } 4 \\
\text { (Kolam } \\
\text { Fakultatif) }\end{array}$ & 6,80 & 1.440 & 43,76 & 48,98 & 15,6 & 5 & 4 & 1,3 & $\begin{array}{c}\text { Sesuai kriteria } \\
\text { desain }\end{array}$ \\
\hline $\begin{array}{l}\text { KOLAM } 5 \\
\text { (Kolam } \\
\text { Aerobik) }\end{array}$ & 7,01 & 1.044 & 87,76 & 21,64 & 10,9 & 5 & 7,65 & 3,5 & $\begin{array}{c}\text { Sesuai kriteria } \\
\text { desain }\end{array}$ \\
\hline $\begin{array}{l}\text { KOLAM } 6 \\
\text { (Kolam } \\
\text { Maturasi I) }\end{array}$ & 7,16 & 1.044 & 23,53 & 28,14 & 10,7 & 5 & 7,49 & 3,5 & $\begin{array}{c}\text { Sesuai kriteria } \\
\text { desain }\end{array}$ \\
\hline $\begin{array}{l}\text { KOLAM } 7 \\
\text { (Kolam } \\
\text { Maturasi II) }\end{array}$ & 6,88 & 1.044 & 36,24 & 42,29 & 10,7 & 5 & 7,49 & 3,5 & $\begin{array}{c}\text { Sesuai kriteria } \\
\text { desain }\end{array}$ \\
\hline $\begin{array}{l}\text { KOLAM } 8 \\
\text { (Kolam } \\
\text { Maturasi III) }\end{array}$ & 7,24 & 1.044 & 33,66 & 33,29 & 10,7 & 5 & 6,85 & 3,2 & $\begin{array}{c}\text { Sesuai kriteria } \\
\text { desain }\end{array}$ \\
\hline $\begin{array}{l}\text { KOLAM } 9 \\
\text { (Kolam } \\
\text { Maturasi IV) }\end{array}$ & 7,35 & 1.044 & 65,05 & 62,12 & 10,7 & 5 & 6,42 & 3 & $\begin{array}{c}\text { Sesuai kriteria } \\
\text { desain }\end{array}$ \\
\hline
\end{tabular}

Sumber: Data penelitian, 2021

Produksi tepung tapioka dengan bahan dasar sebanyak 25 ton singkong yang diolah menghasilkan $500 \mathrm{~kg}$ buangan padat dalam bentuk sludge/lumpur setiap bulannya, dan tiap $5 \mathrm{~m}^{2}$ sludge menyebar ke 9 kolam dengan rata-rata $83,33 \mathrm{Kg} / \mathrm{m}^{2}$.hari. Setelah melakukan analisis data berdasarkan 3 metode evaluasi yang dilakukan, penulis mendapatkan kesimpulan bahwa kedalaman kolam berpengaruh pada efisiensi pengolahan limbah cair. Akibat daripada endapan lumpur yang berlebih maka pengolahan menjadi tidak maksimal. BOD dan COD yang besar yang seharusnya mengendap ke dasar kolam, tetapi karena ada penumpukkan lumpur maka BOD dan COD dalam jumlah besar dari kolam sebelumnya akan terikut ke dalam aliran limbah cair sampai ke outlet. Walaupun efisiensi kolam sangat variatif, namun bisa memperkecil kadar parameter selama proses berlangsung. 
Dari data yang diperoleh dalam 3 metode evaluasi tersebut, ternyata menunjukkan bahwa Kolam 1 (primary pond) dan kolam 2 (secondary pond) dianggap mampu turunkan kadar parameter limbah cair dalam jumlah kecil (atau hanya sebagian besar). Tetapi dalam kolam 3 (Deep Pond), ternyata mengalami masalah dalam progress IPAL tersebut. Maka perlu ditinjau kembali agar tidak bermasalah juga di kolam 4 (Kolam fakultatif). Meskipun Kolam 4 (Kolam Fakultatif) mampu menurunkan kadar berlebih hingga waktu detensi ikut berkurang. Lalu rekomendasi lainnya adalah membangun dinding semen pada seluruh dinding dan alas saluran (ditch) dan kolam.

Selain itu, perlu dilakukan pengerukan lumpur di setiap dasar kolam IPAL dan setiap saluran baik dari inlet maupun outlet, supaya adanya perlu penyeimbangan tinggi lumpur dengan tinggi air dalam kolam dan bila perlu lumpur tetap harus dikuras dan dibuang. Kemudian juga perlu dilakukan pemantauan dan pengujian kadar air limbah/limbah cait di seluruh unit kolam di IPAL PT Sari Tani Sumatera secara internal minimal 1 (satu) kali setiap bulan. Khusus kolam ke-9 (Kolam Maturasi IV), diberikan unit tambahan sebagai pengganti "tempat kontrol air limbah" menjadi unit bak Klorinasi Alkali untuk menyisihkan Sianida (terlarut).

\section{Kesimpulan dan Saran Kesimpulan}

Adapun kesimpulan yang diperoleh dalam penelitian ini adalah bentuk buangan yang dihasilkan yakni buangan padat (kulit singkong yang dikupas dan ampas hasil olahan), cair (air cucian singkong dan air limbah dari proses pembuatan tepung tapioka) dan gas (dari proses pemanasan boiler). Dari hasil kunjungan, penulis mendapatkan informasi kondisi eksisting IPAL PT Sari Tani Sumatera, yakni lahan untuk IPAL PT Sari Tani Sumatera sebesar 2 ha (dari 6 ha yang disediakan). Unit IPAL PT Sari Tani Sumatera berbasis kolam stabilisasi dan memiliki 9 unit kolam dalam kondisi alamiah/natural (terbuka), sehingga dianggap masih aerobik. Adapun rekomendasi yang harus dilakukan dengan diperoleh hasil analisis dan evaluasi data, serta pembahasan kesimpulan terhadap unit IPAL PT Sari Tani Sumatera. Rekomendasi tersebut yakni perlu dilakukan pemantauan pengujian air limbah/limbah cair minimal 1 (satu) kali sebulan secara internal oleh PT Sari Tani Sumatera. Selanjutnya perlu dibangun dinding semen di dinding kolam tersebut, dan penambahan unit Klorinasi Alkali untuk diletakkan di dekat kolam 9 (Kolam Maturasi IV).

Saran

Sebaiknya perlu dilakukan pengujian berkala tanpa ada kesalahan data sampel, seperti perbaikan metode pengambilan sampel air limbah/limbah cair dari unit IPAL di industri manapun. Selain itu sebaiknya perlu dilakukan kecocokan data yang diperoleh dengan metode yang dipakai untuk pengukuran kadar air limbah berdasarkan referensi yang diperoleh (termasuk juga tabel kriteria desain IPAL dan baku mutu air limbah). Terakhir perlu dilakukan kesimpulan data yang lebih lugas untuk bisa memperoleh rekomendasi berdasarkan hasil analisis data yang telah dievaluasi dan referensi yang dipilih.

\section{Ucapan Terima Kasih}

Penulis mengucapkan terima kasih kepada Tuhan Yang Maha Esa yang telah membantu saya secara moril dalam mengerjakan manuskrip ini. Penulis juga mengucapkan terima kasih kepada jurusan Teknik Lingkungan Universitas Sumatera Utara. Penulis mengucapkan terima kasih kepada Dr. Ir. Amir Husin (pembimbing I) dan Muhammad Faisal., ST., MT (pembimbing II) yang telah memberikan ilmu, masukan, dan kritik kepada penulis selama mengerjakan tugas akhir dan jurnal manuskrip ini.

\section{Referensi}

[1] Iskandar, Zulrizka. 2012. Psikologi Lingkungan (Teori dan Konsep). Bandung: PT Refika Aditama.

[2] Mallongi, Anwar. 2017. Dampak Limbah Cair dari Aktivitas Institusi dan Industri. Yogyakarta: Gosyen Publishing.

[3] Asmadi dan Suharno. 2012. Dasar-Dasar Teknik Pengolahan Air Limbah. Yogyakarta: Gosyen Publishing.

[4] Sumut Pos. 5 April 2019. SIWI PENI: JANGAN SAMPAI ADA PABRIK YANG MENCEMARI LINGKUNGAN (Syukuran Ultah ke-23 Tahun, PTPN IV Gelar Aksi Sosial). Medan, Sumatera Utara: Sumut Pos.

[5] KLH Jepang dan KLH Indonesia. 2013. Panduan Penanganan Air Limbah di Pabrik PKS (Sebagai hasil studi kebijakan bersama Indonesia-Jepang (2011-2013) ). Sumatera Utara: KLH Jepang dan KLH Indonesia.

[6] Zulkifli, Arif. 2017. Pengelolaan Limbah Edisi 2. Yogyakarta : Teknosain. 
[7] Riffat, Rumana. 2013. Fundamentals of Wastewater Treatment and Engineering. London: Iwa Publishing and CRC Press.

[8] Rozkošný, Miloš., Kriška, Michal., Šálek, Jan., Bodík,Igor., Istenič, Darja. 2014. Natural Technologies of Wastewater Treatment. Europe : Global Water Partnership Central and Eastern Europe.

[9] Ginting, Perdana. 2017. Sistem Pengelolaan Lingkungan dan Limbah Industri (Cetakan ke-5). Bandung: Penerbit Yrama Widya.

[10] Said, Nusa Idaman. 2017. Teknologi Pengolahan Air Limbah. Jakarta: Penerbit Erlangga

[11] Howeler, Reinhardt H.2011. The Cassava Handbook: A Reference Manual Based On The Asian Regional Cassava Training Course Held In Thailand (Section: Recent Trends In Production And Utilization Of Cassava In Asia). Thailand: Centro Internacional de Agricultura Tropical (CIAT), the Department of Agriculture DOA) and the Thai Tapioca Development Institute (TTDI) of Thailand (With financial support from the Nippon Foundation, Tokyo, Japan)

[12] China \& Cambodia and UNDP. 2015. Cassava Handbook (China-Cambodia-UNDP Trilateral Cooperation Cassava Project Phase II March 2015). Phnom Penh: UNDP.

[13] Suharto, Ign. 2011. Limbah Kimia Dalam Pencemaran Udara dan Air. Yogyakarta: Penerbit Andi

[14] Situmorang, Manihar. 2012. Kimia Lingkungan. Medan: FMIPA Unimed

[15] Qasim, Syed R., Zhu, Guang. 2018. Wastewater Treatment and Reuse Theory and Design Examples (Volume 1: Principles and Basic Treatment). United States of America: CRC Press. 